\title{
Fever is associated with third ventricular shift after intracerebral hemorrhage: Pathophysiologic implications
}

\author{
Anupa Deogaonkar, Michael De Georgia. Charles Bae. Alex Abou-Chebl, John Andrefsky \\ Department of Neurology, Cleveland Clinic Foundation, Cleveland, USA
}

\begin{abstract}
Background: Studies have shown the detrimental effect of increased temperature on brain injury. Fever is common after intracerebral hemorrhage (ICH). The term 'central fever' ? is often used when no cause is identified. Aim: The aim of the study was to determine the correlation of fever with third ventricular shift in 61 patients with $\mathrm{ICH}$ and hypothesize about the mechanism of fever. Setting: Neurointensive Care Unit Design: Prospective observational study. Materials and Methods: From August 1999 to April 2000, data from 61 patients with $\mathrm{ICH}$ were prospectively collected including maximum temperature (Tmax) and fever $\left(T>37.5^{\circ} \mathrm{C}\right)$ at 24 , 48,72 and 96 hours, ICH volume, and third ventricular shift. Outcome measures included discharge mortality, 3-month National Institute of Health Stroke Scale (NIHSS), modified Rankin Scale (mRS), and Barthel Index (BI). Statistical Analysis: Spearman correlation coefficient, Mann-Whitney test, and logistic regression were used to assess relationships. Results: Fifty-six per cent of patients had fever in the first 24 hours and $53 \%$ for at least two consecutive days. There was a correlation between $\mathrm{ICH}$ volume and Tmax at 24 hours $(P=0.04)$ and 72 hours $(P=0.03)$ and fever at 24 hours $(P=0.039)$ and 72 hours $(P=0.036)$. Tmax at 72 hours correlated with third ventricular shift $(P=0.01)$. Those with shift were more likely to have fever within the first 72 hours $(P=0.049)$ and worse outcome. Fever at 72 hours was associated with a higher discharge mortality $(P=0.046)$ and trend of a worse 3 -month NIHSS score $(P=0.06)$. Conclusion: Fever is common after $\mathrm{ICH}$ and correlates with $\mathrm{ICH}$ volume and third ventricular shift suggesting a role of hypothalamic compression in "central fever." There was a trend towards a worse outcome with fever.
\end{abstract}

Key Words: Fever, intracerebral hemorrhage, hypothalamus

There is a growing body of literature demonstrating the detrimental effects of fever, whatever the cause, after brain injury. Animal models of global and focal cerebral ischemia, have shown that even mild hyperthermia exacerbates ischemic neuronal injury. ${ }^{[1-11]}$ Fever is common after intracerebral hemorrhage. ${ }^{[12,13]}$ Possible causes include infections of the urinary and respiratory tract, thrombophlebitis, and drug reactions. Often the term "central fever" is used when no obvious cause can be identified. "Central fever" has most often been attributed to cytokine-related elevation of the hypothalamic set point. Mechanical compression of the hypothalamus has been demonstrated in animal models to cause fever. ${ }^{[14]}$ We hypothesized that patients with third ventricular shift after ICH would be more likely to become febrile due to hypothalamic compression than patients without third ventricular shift. We analyzed 61 patients with ICH for incidence of fever and correlation with third ventricular shift.

\section{Materials and Methods}

After Institutional Review Board approval at The Cleveland Clinic Foundation, we prospectively collected data on 61 patients with spontaneous ICH, with or without intraventricular hemorrhage (between August 1999 to April 2000) consecutively admitted to the Neurological Intensive Care Unit. Exclusion criteria included subarachnoid hemorrhage (SAH), hemorrhagic transformation, subdural hematoma, epidural hematoma, hospital admission $>24$ hours, prior ischemic stroke. Data collected included age, gender, race, vascular risk factors, Glasgow Coma Scale (GCS) score and National Institute of Health Stroke Scale (NIHSS) score on admission. Hemorrhage location and volume were recorded from the admission brain Computerized Tomography (CT) scan (volume was calculated using the $\mathrm{ABC} / 2$ method). ${ }^{[15,16]}$ The presence of third ventricular shift was determined from admission brain CT scan by a neuroradiologist blinded to the patients' clinical status and temperature. The amount of shift was classified as mild $(1-5 \mathrm{~mm})$, moderate $(5-10 \mathrm{~mm})$, or severe $(>10 \mathrm{~mm})$. Hourly temperatures and maximal temperatures (Tmax) at 24, 48, 72 and 96 hours were recorded. Fever was defined as a body temperature greater than $37.5^{\circ} \mathrm{C}$. Patient outcome measures included NIHSS score, modified Rankin Scale (mRS) score, and Barthel Index (BI) at 96 hours, at 1 week, at discharge and at 3 months.

Statistical analysis: Spearman Correlation Coefficient, Mann Whitney test and logistic regression analysis were used to assess 
relationships. Odds ratios (OR) and 95\% confidence intervals (CI) are reported for each comparison. No adjustment was made for multiple comparisons over time.

\section{Results}

Out of 61 patients in the study, $25(41 \%)$ were males and $36(59 \%)$ were females. Demographic data for the 61 patients are reported in Table 1 . The mean age was $65 \pm 16$ years (range 30-92). The mean admission GCS score was $8.8 \pm 4.8$ and the mean NIHSS score was $20.05 \pm 11.5$. The most common hemorrhage location was lobar $(63 \%)$ followed by deep basal ganglia $(27 \%)$ and infratentorial $(10 \%)$. The mean ICH volume was $48.9 \pm 52.4 \mathrm{ml}$. Fifty-six percent of patients had fever in the first 24 hours, $53 \%$ had fever for at least two consecutive days. The mean Tmax overall was $38.0 \pm 0.9^{\circ} \mathrm{C}$. The mean Tmax in the first 72 hours was $38.5 \pm 0.9^{\circ} \mathrm{C}$. Thirtytwo of 58 patients $(55.1 \%$ : data missing in 3 patients) had third ventricular shift greater than $1 \mathrm{~mm}$ (Figure 1). Fifteen of these 32 patients (47\%) had mild shift, 9 (28\%) had moderate shift and $8(25 \%)$ had severe shift of the third ventricle. Overall, the mean third ventricular shift was $3.6 \pm 4.5 \mathrm{~mm}$. There was a correlation between the presence of third ventricular shift and Tmax at 72 hours $(P=0.01$, SSC $=0.37)$ and between third ventricular shift and presence of fever within 72 hours $(P=0.049, \mathrm{SSC}=0.37)$. Fifty-nine per cent vs. $44 \%$ patients had fever during the first 24 hours, $64 \%$ vs. $48 \%$

\begin{tabular}{|c|c|}
\hline \multicolumn{2}{|c|}{ Table 1: Patient characteristics $(n=61)$} \\
\hline Age (years) & $65 \pm 16$ \\
\hline \multicolumn{2}{|l|}{ Gender } \\
\hline Male & $25(41 \%)$ \\
\hline Female & $36(59 \%)$ \\
\hline \multicolumn{2}{|l|}{ Vascular Risk Factors } \\
\hline Hypertension & $51(84 \%)$ \\
\hline Diabetes Mellitus & $19(31 \%)$ \\
\hline Coagulopathy & $20(33 \%)$ \\
\hline Alcoholism & $7(11.4 \%)$ \\
\hline${ }^{*}$ GCS score (Mean \pm SD) & $8.8 \pm 4.8$ \\
\hline+ NIHSS score (Mean \pm SD) & $20.05 \pm 11.5$ \\
\hline \multicolumn{2}{|l|}{$\$ \mid \mathrm{CH}$ Location } \\
\hline Lobar & 39 \\
\hline Frontal- Parietal & 19 \\
\hline Parietal- Temporal & 17 \\
\hline Occipital & 3 \\
\hline Deep & 15 \\
\hline Basal Ganglia & 6 \\
\hline Thalamus & 9 \\
\hline Infratentorial & 7 \\
\hline Brainstem & 3 \\
\hline Cerebellum & 4 \\
\hline qWith IVH & 20 \\
\hline \multicolumn{2}{|l|}{$\mathrm{ICH}$ volume } \\
\hline Mean \pm SD & $48.9 \pm 52.4 \mathrm{ml}$ \\
\hline Median & $38.5 \mathrm{ml}$ \\
\hline \multicolumn{2}{|l|}{$3^{\text {rd }}$ Ventricular Shift } \\
\hline Number & $32 / 58$ (data missing for 3 ) \\
\hline Mean & $3.6 \pm 4.5 \mathrm{~mm}$ \\
\hline Median & $6 \mathrm{~mm}$ \\
\hline
\end{tabular}

${ }^{*}$ GCS $=$ Glasgow Coma Scale; ${ }^{+N I H S S}=$ National Institute of Health Stroke Scale; $\S \mathrm{ICH}=$ Intracerebral Hemorrhage; ฯIVH = Intraventricular Hemorrhage

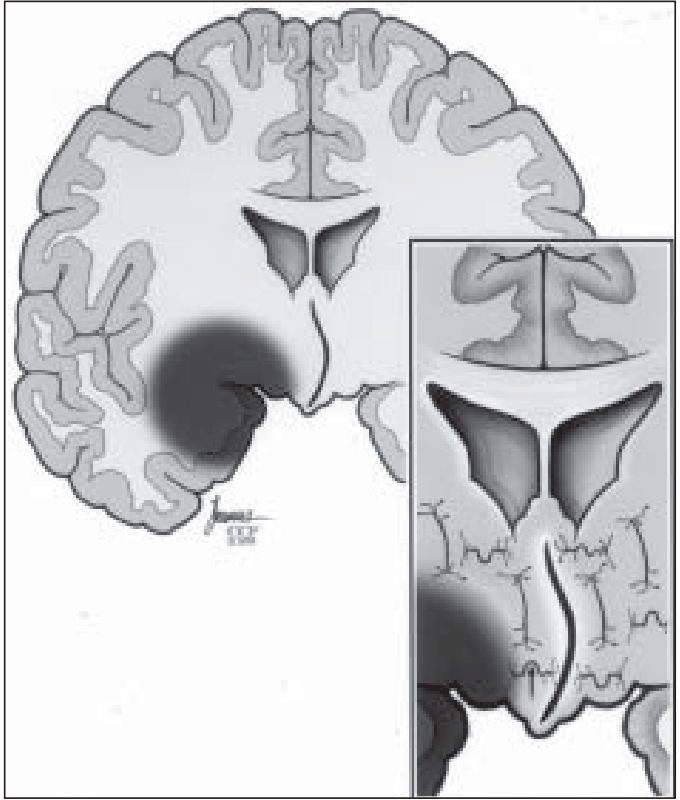

Figure 1: CT scan showing third ventricular shift due to intracerebral hemorrhage

patients had fever during 24-48 hours and $86 \%$ vs. $46 \%$ had fever during 48-72 hours in patients with shift as compared to patients without shift $(P=0.09)$. Table 2 shows incidence of infection, intubation and presence of deep vein thrombosis (DVT) in all patients. Multivariate analysis showed no confounding effects of infection, intubation or thrombophlebitis.

There was a correlation between ICH volume and Tmax at 24 hours $(P=0.04, \mathrm{SCC}=0.26)$ and at 72 hours $(P=0.03$, $\mathrm{SCC}=0.32)$. There was also a correlation between ICH volume and the presence of fever at 24 hours $(P=0.039$, SCC $=$ $0.26)$ and at 72 hours $(P=0.036, \mathrm{SCC}=0.32)$ (Table 3$)$. Models predicting hospital mortality using baseline NIHSS, GCS, ICH volume and other covariables are described in Table 4. NIHSS and GCS were not shown to differ on the prediction

\begin{tabular}{lc}
\hline \multicolumn{2}{c}{ Table 2: Incidence of infection in all patients $(\mathbf{n = 6 1 )}$} \\
\hline Factor & $\mathbf{n}(\%)$ \\
Intubation & $24(42.6)$ \\
Positive urinalysis & $6(10)$ \\
Positive blood culture & $1(1.6)$ \\
Positive cerebrospinal fluid cultures & $1(1.6)$ \\
Positive sputum culture & $3(5)$ \\
Positive finding on chest X-ray & $11(18)$ \\
Deep Vein Thrombosis & $1(1.6)$
\end{tabular}

Table 3: Correlation of ICH Volume with Tmax and Fever

\begin{tabular}{lcc}
\hline Variable & \multicolumn{2}{c}{ Time } \\
\cline { 2 - 3 } & 24 hours & $\mathbf{7 2}$ hours \\
*ICH Volume and +Tmax & \&CC $=0.26 P=0.04$ & SCC $=0.32 P=0.03$ \\
ICH Volume and fever & ${ }^{\top} \mathrm{OR}\left(95 \%{ }^{* *} \mathrm{Cl}\right)=$ & $\mathrm{OR}(95 \% \mathrm{Cl})=$ \\
& $1.01(1.00,1.02)$ & $1.02(1.00,1.04)$ \\
& $P=0.039$ & $P=0.036$ \\
\hline
\end{tabular}

${ }^{*} \mathrm{ICH}=$ Intracerebral Hemorrhage; ${ }^{+}$Tmax $=$Maximum Temperature; ${ }^{\S} \mathrm{SCC}=$ Spearman Correlation Coefficient; ${ }^{\top} \mathrm{OR}=$ Odds Ratio; ${ }^{* *} \mathrm{Cl}=$ Confidence interval 
Table 4: Logistic regression analysis predicting hospital mortality

\begin{tabular}{|c|c|c|c|c|}
\hline \multicolumn{3}{|c|}{$\begin{array}{l}\text { Model: Baseline *NIHSS, } \\
+ \text { ICHvol, predictor }\end{array}$} & \multicolumn{2}{|c|}{$\begin{array}{l}\text { Model: Baseline }{ }^{\S} \mathrm{GCS} \text {, } \\
\text { ICHvol, predictor }\end{array}$} \\
\hline Predictor & $\begin{array}{l}\text { Predictor } \\
P \text { value }\end{array}$ & $\begin{array}{c}\text { Baseline } \\
\text { NIHSS } \\
P \text { value }\end{array}$ & $\begin{array}{l}\text { Predictor } \\
P \text { value }\end{array}$ & $\begin{array}{c}\text { Baseline GCS } \\
P \text { value }\end{array}$ \\
\hline ICHvol & 0.037 & $<0.001$ & 0.014 & $<0.001$ \\
\hline Male & 0.68 & $<0.001$ & 0.57 & $<0.001$ \\
\hline White & 0.51 & $<0.001$ & 0.37 & $<0.001$ \\
\hline${ }^{* *} \mathrm{HTN}$ & 0.39 & $<0.001$ & 0.36 & $<0.001$ \\
\hline ++DM & 0.16 & $<0.001$ & 0.31 & $<0.001$ \\
\hline "ETOH & 0.16 & $<0.001$ & 0.27 & $<0.001$ \\
\hline Coagulopathy & 0.80 & $<0.001$ & 0.71 & $<0.001$ \\
\hline Intubated & 0.93 & $<0.001$ & 0.99 & 0.008 \\
\hline Side Left & 0.50 & $<0.001$ & 0.26 & $<0.001$ \\
\hline Age & 0.73 & $<0.001$ & 0.49 & $<0.001$ \\
\hline IIVH & 0.004 & $<0.001$ & 0.12 & $<0.001$ \\
\hline
\end{tabular}

${ }^{*} \mathrm{NIHSS}$ indicates National Institute of Health Stroke Scale; ${ }^{+} \mathrm{CH}$ vol. indicates Intracerebral Hemorrhage volume; § GCS indicates Glasgow Coma Scale Score; ${ }^{* *} \mathrm{HTN}$ indicates history of hypertension; ${ }^{++} \mathrm{DM}$ indicates history of Diabetes Mellitus; "ETOH indicates history of ethyl alcohol consumption; "IVH indicates Intraventricular Hemorrhage

\begin{tabular}{|c|c|c|}
\hline $\begin{array}{l}\text { 3-month functional } \\
\text { outcome }\end{array}$ & Patients & $\begin{array}{l}P \text { value comparing } \\
\text { correlations }\end{array}$ \\
\hline NIHSS & $\begin{array}{l}\text { 3-month survivors } \\
\text { all patients }\end{array}$ & $\begin{array}{l}0.37 \\
0.004\end{array}$ \\
\hline GCS & $\begin{array}{l}\text { 3-month survivors } \\
\text { all patients }\end{array}$ & $\begin{array}{l}0.66 \\
0.002\end{array}$ \\
\hline Barthel's Index & $\begin{array}{l}\text { 3-month survivors } \\
\text { all patients }\end{array}$ & $\begin{array}{l}0.31 \\
0.002\end{array}$ \\
\hline Modified Rankin Score & $\begin{array}{l}\text { 3-month survivors } \\
\text { all patients }\end{array}$ & $\begin{array}{l}0.37 \\
0.018\end{array}$ \\
\hline
\end{tabular}

*NIHSS indicates National Institute of Health Stroke Scale; +GCS indicates Glasgow Coma Scale Score

of hospital mortality. Other factors were not important predictors of mortality.

Table 5 shows correlation between baseline scales and functional outcome at 3 months for all patients. Baseline NIHSS and ICH volume correlated with 3-month outcomes than GCS and ICH volume. Fever at 72 hours was associated with a higher mortality rate $(P=0.046)$ and a trend of a worse NIHSS score at 3 months $(P=0.06)$. No worse outcome was observed when measured by Barthel Index or mRS.

Univariate analysis of shift and continuous outcome at 3 months showed that patients with any shift have poor outcome ( $P=0.015$ for NIHSS, $P=0.014$ for Barthel's Index, $P=0.015$ for $\mathrm{mRS}$ ) and are 3.3 times more likely to die at discharge vs. those with no shift $(P=0.027)$. Even after adjusting for fever in multivariate analysis, in all patients, any shift was associated with poorer outcome at 3 months than no shift ( $P=0.015$ for NIHSS, $P=0.014$ for Barthel's Index, $P=0.015$ for $\mathrm{mRS})$.

\section{Discussion}

Our study demonstrates a correlation of fever with ICH vol- ume and third ventricular shift. There was a correlation between ICH volume and Tmax at 24 hours and at 72 hours. There was also a correlation between ICH volume and the presence of fever at 24 hours. In our study, fever at 72 hours after ICH was associated with a higher mortality rate and a trend towards a worse neurological outcome at 3 months.

It has long been recognized that fever is common following brain injury and particularly in patients with ICH. Aring and Merrit, in 1935, were the first to report that fever was more common in patients with hemorrhagic stroke compared with ischemic stroke. ${ }^{[17]}$ This has been further confirmed by more recent studies. Kilpatrick and coworkers reported that among patients admitted to a neurological intensive care unit, those with SAH and ICH had the highest incidence of fever. ${ }^{[13]}$ Estratopoulos and coworkers reported fever in $85 \%$ of patients with primary ICH within the first 48 hours. ${ }^{[18]}$ Schwarz and coworkers reported fever in $91 \%$ of patients in the first 72 hours. ${ }^{[12]}$ In our study, over half of the patients $(56 \%)$ had fever within the first 24 hours of admission to the neurological intensive care unit.

Common causes of fever after ICH include infections of the urinary and respiratory tract, thrombophlebitis, and drug reactions. Often the term "central fever" is used in patients when no cause can be identified. "Central fever" has most often been attributed to cytokine-related elevation of the hypothalamic set point. ${ }^{[14]}$ Experimental models suggest that elevated prostaglandin levels (PG-E2) and thromboxane B2 may also play a role in "central fever". ${ }^{[19]}$ Direct hypothalamic damage can also cause fever. Elevated body temperature in rats has been induced with anterior and preoptic ischemia ${ }^{[20]}$ and medial hypothalamic ischemia. ${ }^{[21]}$ Fever has been induced by direct injury of the hypothalamus from acute mechanical puncture $^{[22]}$ or electrical shock. ${ }^{[23]}$ Clar and coworkers, in a rat model, showed reversible disturbances in temperature regulation from direct hypothalamic compression. ${ }^{[24]}$ In our study, correlation of fever with hemorrhage volume and third ventricular shift suggests a possible role of hypothalamic compression as a cause of "central fever." Anatomically, temperature-sensitive neurons in the hypothalamus are oriented perpendicular to the third ventricle such that dendrites project both laterally, to receive information from ascending fibers of the median forebrain bundle, and medially, to receive information from periventricular fibers and cerebrospinal fluid. ${ }^{[25]}$ This morphology of temperature-sensitive and temperatureinsensitive neurons around the third ventricle is shown in Figure 2. A large hemorrhage volume that results in the shift of the third ventricle may cause these hypothalamic dendrites to buckle and thereby disrupt temperature homeostasis.

Fever is associated with a worse outcome after brain injury. ${ }^{[26-}$ ${ }^{28]}$ A recent meta-analysis showed that in patients with ischemic stroke, fever is associated with a marked increase in morbidity and mortality. ${ }^{[29-34]}$ Few studies have examined the relationship of fever and outcome in patients with intracerebral 


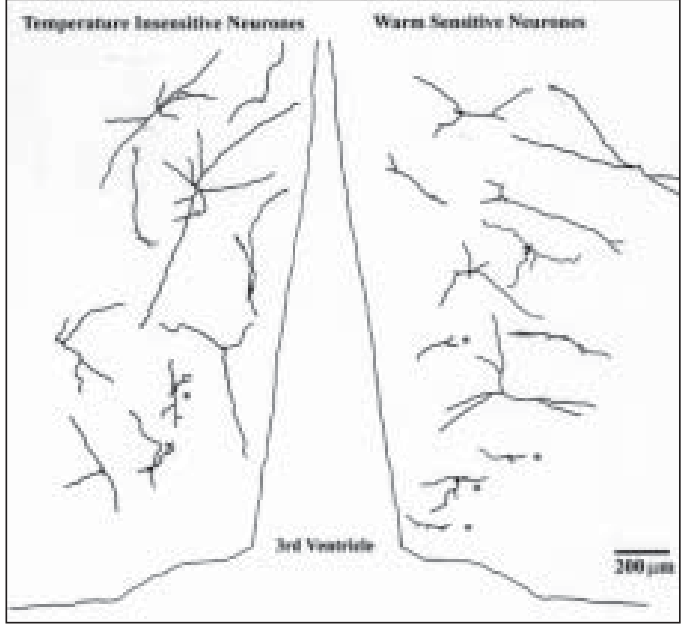

Figure 2: Temperature-insensitive neurons align parallel and temperature-sensitive neurons align perpendicular to the third ventricle (recorded from neurons in rat hypothalamic tissue slices) Reprinted from the Journal of Physiology 2001 December 1; 537(Pt 2):521-35 with permission from the Physiological Society

hemorrhage. Schwarz and coworkers found that fever was independently associated with a worse outcome. ${ }^{[12]}$ A recently reported study by Szczudlik et $a l^{[35]}$ demonstrated that increased body temperature is not an independent predictor of 30-day mortality after ICH. However, the authors concluded that patients with hyperthermia on the first day of hospitalization have greater 30-day mortality and worse functional status 30 days after stroke, but increased body temperature is not an independent predictor of 30-day mortality after ICH. In our study, fever at 72 hours after ICH was associated with a higher mortality rate and a trend towards a worse neurological outcome at 3 months.

Limitations of this study include the small patient population and inconsistent temperature monitoring. A larger prospective study with continuous temperature monitoring is required to confirm our findings. Although it has been previously shown by Arboix et $a l^{[36]}$ that the site of bleeding determines the clinical spectrum and in-hospital mortality in spontaneous ICH, our results were not analyzed to study the outcome according to the site of bleeding.

In summary, our results show that the incidence of fever after ICH is high with most patients having fever in the first 24 hours after admission. Correlation of fever with hemorrhage volume and third ventricular shift suggests a possible role of hypothalamic compression in "central fever" after ICH. There was a trend towards a worse outcome with fever in our patients.

\section{References}

1. Baena RC, Busto R, Dietrich WD, Globus MY, Ginsberg MD. Hyperthermia delayed by 24 hours aggravates neuronal damage in rat hippocampus following global ischemia. Neurology 1997;48:768-73.

2. Busto R, Dietrich WD, Globus MY, Valdes I, Scheinberg P, Ginsberg M. Small differences in intra-ischemic brain temperature critically determine the extent of ischemic neuronal injury. J Cereb Blood Flow Metab 1987;7:729-38.
3. Dietrich WD, Alonso O, Halley M, Busto R. Delayed posttraumatic brain hyperthermia worsens outcome after fluid percussion brain injury: A light and electron microscopic study in rats. Neurosurgery 1996;38:533-41.

4. Coimbra C, Boris-Moller F, Drake M, Wieloch T. Diminished neuronal damage in the rat brain by late treatment with the antipyretic drug dipyrone or cooling following cerebral ischemia. Acta Neuropathol (Berl) 1996;92:447-53.

5. Coimbra C, Drake M, Boris-Moller F, Wieloch T. Long-lasting neuroprotective effect of postischemic hypothermia and treatment with an anti-inflammatory/ antipyretic drug. Evidence for chronic encephalopathic processes following ischemia. Stroke 1996;27:1578-85.

6. Dietrich WD, Busto R, Valdes I, Loor Y. Effects of normothermic versus mild hyperthermic forebrain ischemia in rats. Stroke 1990;21:1318-25.

7. Ginsberg MD, Busto R. Combating hyperthermia in acute stroke: A significant clinical concern. Stroke 1998;29:529-34.

8. Kim Y, Busto R, Dietrich WD, Kraydieh S, Ginsberg MD. Delaved postischemic hyperthermia in awake rats worsens the histopathological outcome of transient focal cerebral ischemia. Stroke 1996;27:2274-80.

9. Meden P, Overgaard K, Pedersen H, Boysen G. The influence of body temperature on infaret volume and thrombolytic therapy in a rat embolic stroke model. Brain Res 1994;647:131-8.

10. Memezawa H, Zhao Q, Smith ML, Siesjo BK. Hyperthermia nullifies the ameliorating effect of dizoclipine maleate (MK-801) in focal cerebral ischemia. Brain Res 1995;670:48-52.

11. Minamisawa H, Smith ML, Siesjo BK. The effect of mild hyperthermia and hypothermia on brain damage following 5,10 , and 15 minutes of forebrain ischemia. Ann Neurol 1990;28:26-33.

12. Schwarz S, Hafner K, Aschoff A, Schwab S. Incidence and prognostic significance of fever following intracerebral hemorrhage. Neurology 2000;54:354-61.

13. Kilpatrick M, Lowry D, Firlik A, Yonas H, Marion D. Hyperthermia in the neurosurgical intensive care unit. Neurosurgery 2000;47;4:850-5.

14. Dinarello C, Cannon J, Wolff S. New concepts on the pathogenesis of fever. Rev Infect Dis $1988 ; 101: 168-89$

15. Broderick JP, Brott TG, Duldner JE, Tomsick T, Huster G. Volume of intracerebral hemorrhage: A powerful and easy-to-use predictor of 30-day mortality. Stroke 1993;24:987-93.

16. Broderick JP, Brott T, Grotta J. Intracerebral hemorrhage volume measurement. Stroke 1994;25;5:1081.

17. Aring C, Merritt H. Differential diagnosis between cerebral hemorrhage and cerebral thrombosis; a clinical and pathological study of 245 cases. Arch Intern Med 1935;56:435-56.

18. Estratopoulos A, Voyaki S, Leuow M. Fever from intracerebral hemorrhage. therapeutic effect of Naproxen. presented in $56^{\text {th }}$ International Conference of Stroke and $2^{\text {nd }}$ Conference of the Mediterranean Stroke Society 2001. Istanbul, Turkey. (Abstract)

19. Dewitt D, Kong D, Lyeth B, Jenkins L, Hayes R, Wooten E, et al. Experimental traumatic brain injury elevates brain prostaglandin E2 and thromboxane B2 levels in rats. J Neurotrauma 1988;5:303-13.

20. Zhao Q, Memezawa H, Smith M, Siesjo B. Hyperthermia complicates middle cerebral artery occlusion induced by an intraluminal filament. Brain Res 1994;649:253-9.

21. He Z, Yamawaki T, Yang S, Day AL, Simpkins JW, Naritomi H. Experimental model of small deep infarcts involving the hypothalamus in rats: Changes in body temperature and postural reflex. Stroke 1999;30:2743-51.

22. Ackerman D, Rudy T. Thermoregulatory characteristies of neurogenic hyperthermia in the rat. J Physiol 1980;307:59-70.

23. Nathan MA, Reis D. Fulminating arterial hypertension with pulmonary edema from release of adrenomedullary catecholamines after lesions of the anterior hypothalamus in the rat. Circ Res 1975;37:226-35.

24. Clar HE, Disturbances of the hypothalamic thermoregulation. Acta Neurochir (Wien) 1985;75;106-12.

25. Griffin JD, Saper CB, Boulant JA, Synaptic and morphological characteristies of temperature-sensitive and -insensitive rat hypothalamic neurones. J Physiol 2001;537:521-35.

26. Sazbon L, Groswasser Z. Outcome in 134 patients with prolonged posttraumatic unawareness. Part 1: Parameters determining late recovery of consciousness. J Neurosurg 1990;72:75-80.

27. Stover SL, Zeiger HE Jr. Head injury in children and teenagers; functional recovery correlated with the duration of coma. Arch Phys Med Rehabil $1976 ; 57: 201-5$

28. Auer LM, Gell G, Richling B, Oberbauer R, Clarici G, Heppner F. Predicting lethal outcome after severe head injury- a computer-assisted analysis of neurological symptoms and laboratory values. Acta Neurochir (Wien) 1980;52:22538 .

29. Reith J, Jorgensen HS, Pedersen PM, Nakayama H, Raaschou HO, Jeppesen LL, et al. Body temperature in acute stroke: relation to stroke severity, infaret size, mortality, and outcome. Lancet 1996;347:422-5.

30. Hajat C, Hajat S, Sharma P, Effects of poststroke pyrexia on stroke outcome: A meta-analysis of studies in patients. Stroke 2000;31:410-4.

31. Azzimondi G, Bassein L, Nonino F, Fiorani L, Vignatelli L, Re G, et al. Fever 
in acute stroke worsens prognosis- A prospective study. Stroke 1995;26:20403 .

32. Castillo J, Davalos A, Marrugat J, Noya M. Timing for fever-related brain damage in acute ischemic stroke. Stroke 1998;29:2455-60.

33. Hindfelt B. The prognostic significance of subfebrility and fever in ischemic cerebral infarction. Acta Neurol Scand 1976;53:72-9.

34. Greisman L, Mackowiak P. Fever: beneficial and detrimental effects of antipyreties. Curr Opin Infect Dis 2002;15:241-5.
35. Szczudlik A, Turaj W, Slowik A, Strojny .J Hyperthermia is not an independent predictor of greater mortality in patients with primary intracerebral hemorrhage. Med Sci Monit 2002;8:702-7.

36. Arboix A, Comes E, Garcia-Eroles L, Massons .J, Oliveres M, Balcells M, et at. Site of bleeding and early outcome in primary intracerebral hemorrhage; Acta Neurol Scand 2002;105:282-8.

Accepted on 06-02-2005

\section{Invited Comments}

Increased body temperature at stroke onset is a poor prognostic factor. In patients with spontaneous supratentorial intracerebral hemorrhage, the duration of fever is associated with poor recovery and seems to be an independent predictor of outcome. There is a considerable body of evidence based on experimental studies showing that increased body temperature when present during or after a period of acute stroke exacerbates the degree of resulting neuronal injury. Temperature has a significant influence on intracerebral metabolism. Hyperthermia increases the release of excitatory neurotransmitters (glutamate, gamma-aminobutyric acid, and glycine) and oxygen free radicals, causes more extensive bloodbarrier breakdown, impairs recovery of energy metabolism via increased enzymatic inhibition of protein kinases and worsens cytoskeletal proteolysis, all proposed mechanisms of late neuronal death, mainly in the ischemic penumbra, the site where temperature-dependent stroke progression occurs. In addition, it seems that hyperthermia exaggerates the development of brain edema in patients with intracerebral hemorrhage. A recent meta-analysis ${ }^{[1]}$ showed that both morbidity and mortality were significantly higher in pyrexial than apyrexial stroke patients, confirming that hyperthermia within the first 24 hours of stroke onset is associated with significantly greater morbidity.

Infections (mainly of pulmonary and urinary sources), thrombophlebitis, and drug reactions are the most frequent causes of hyperthermia in patients with stroke. "Central" or "neurogenic" fever is another potential etiology. Direct damage to the thermoregulatory centers in the hypothalamus and brainstem has been reported as the cause of severe hyperther-

\section{Invited Comments}

Fever is frequent in patients with acute neurolgic insult admitted to neurological intensive care units (ICU). ${ }^{[1]-[3]}$ There is growing evidence that elevated body temperature may be deleterious in this population. Fever was independently associated with a longer ICU and hospital length of stay (LOS) in mia in experimental models. The mechanical irritation of the hypothalamic thermoregulatory centers by the intraventricular blood can also produce hyperthermia and may account for the high incidence of fever after supratentorial intracerebral hemorrhage, especially in patients with ventricular hemorrhage. ${ }^{[2]}$

The study of Deogaonkar et al shows that in patients with intracerebral hemorrhage, the presence of fever correlates with "third ventricular shift", suggesting a role of hypothalamic compression as a cause of "central fever". This study also confirms a higher mortality rate and a trend towards a worse neurological outcome in patients with hyperthermia.

Hyperthermia, independently of its cause, may aggravate the outcome of stroke patients and should be promptly reversed with appropriate antipyretic agents. Lowering temperature in febrile stroke patients is at least as important as antimicrobial treatment in case of infection. Body temperature should be maintained in a safe normothermic range (e.g., between $36.7^{\circ} \mathrm{C}$ and $37.0^{\circ} \mathrm{C}$ ) for at least several days after stroke onset.

Adrià Arboix

Acute Stroke Unit, Service of Neurology, Hospital del Sagrat Cor, Barcelona, Spain.E-mail: aarboix@hscor.com

\section{References}

1. Hajat C, Hajat S, Sharma P. Effects of poststroke pyrexia on stroke outcome. A meta-analyisis of studies in patients. Stroke 2000;31:410-4.

2. Schwartz S, Häfner K, Med C, Aschoff A, Schwab S. Incidence and prognostic significance of fever following intracerebral hemorrhage. Neurology $2000 ; 54: 354-61$. a dose-dependent manner, and also with higher mortality rate, and worse outcome. The relationship between elevated body temperature and hospital LOS was significant in all diagnosis groups except spine disease, brain tumors, and subdural hematomas. ${ }^{[3]}$ 
The incidence of fever after supratentorial intracerebral hemorrhage (ICH) is high, especially in patients with intraventricular hemorrhage (IVH). ${ }^{[4]}$ Both ICH and subarchnoid hemorrhage (SAH) increase the risk of developing of unexplained, 'central' fever. ${ }^{[2],[4]}$ The study by Diogaonkar et al. ${ }^{[5]}$ in this issue of the journal confirms the same. Refractory high fever $\left(>42^{\circ} \mathrm{C}\right)$ in the immediate aftermath of massive supratentorial or brainstem ICH is well described, and is the basic observation supporting 'central fever' as a clinical entity ${ }^{[6]-[8]}$ What factors increase the risk for developing 'central fever' in patients with ICH is not clear. In the Columbia study intraventricular catheter (IVC) placement in patients with SAH and ICH was independently associated with 'central fever.' ${ }^{[2]}$ Fever is generally has been associated with IVH in ICH patients. ${ }^{[4]}$ Both these observations suggest that IVH can cause 'central fever.' The study by Diogaonkar et al. ${ }^{[5]}$ demonstrates the relationship between elevated body temperature and third ventricular shift. How IVH and third ventricular shift affect hypothalamic function and cause 'central fever' is speculative. ${ }^{[9]}$ One of the possible mechanisms as suggest by Diogaonkar et al. ${ }^{[5]}$ is by hypothalamic compression resulting in hypothalamic dendrites to buckle and thereby disruption temperature homeostasis. In patients with IVH it may be related to direct hemotoxic damage to thermoregulatory centers. ${ }^{[5]}$

The risk of developing fever with these risk factors, IVH and third ventricular shift, in patients with ICH is sufficiently high to warrant early active intervention to maintain normothermia and prevent fever. The impact of elevated body temperature control on outcome in patients with acute brain insult, however, has not yet been tested. There has been no prospective study of an attempt to maintain euthermia in patients with acute brain insults. Thus it remains unproven as to whether control of elevated body temperature could improve outcome or decrease hospital LOS. Conventional means of treating fever are not very effective. Acetaminophen and aircooling blankets effectively treat elevated body temperature in less than half of the patients. ${ }^{[10]}$ Recently studies showed catheter-based heat exchange system significantly improves fever reduction in NICU patients. ${ }^{[11]}$ As we now have an effective tool, catheter-based heat exchange system, for treating fever in this population of patients, an outcome study is possible and should be performed.

\section{J. M. K. Murthy Department of Neurology, The Institute of Neurological Sciences, CARE Hospital, Hyderabad, India. E-mail: jmkmurthy@satyam.net.in}

\section{Reference}

1. Kilpatrick MM, Lowery DW, Firlik AD, Yonas H, Marion DW. Hyperthermia in the neurosurgical intensive care unit. Neurosurgery 2000; 47:850-856.

2. Commichau C, Scarmeas N, Mayer SA. Risk factors for fever in the neurologic intensive care unit. Neurology 2003; 60: 837-41.

3. Diringer M, Reaven NL, Funk SE, Uman GC. Elevated body temperature independently contributes to increased length of stay in neurolgic intensive care unit patient. Crit Care Med 2004; 32; 1489-1405.

4. Schwarz S, Hafner K, Aschoff A, Schwab S. Incidence and prognostic significance of fever following intracerebral hemorrhage. Neurology 2000; 54: 354 361.

5. Diogaonkar A, De Georgia M, Bae C, Abou-Chebl A, Andrefsky J. Fever is associated with third ventricular shift after intracerebral hemorrhage: pathophysiological implications. Neurol India 2005; 53: 202-6.

6. Chin RL. High temperature with cerebral hemorrhage. Ann Emerg Med 1999; 34: 411. Letter

7. Kitanaka C, Inoh Y, Toyoda T, Sasaki T, Eguchi T. Malignant brain stem hyperthermia caused by brain stem hemorrhage. Stroke 1994; 25: 518-520.

8. Erickson TC. Neurogenic hyperthermia (a clinical syndrome and its treatment). Brain 1939; 62: 172-190.

9. Shibata M. Hyperthermia in brain hemorrhage. Med Hypoth 1998; 50: 185190.

10. Mayer SA, Commichau C, Scarmeas N, et al. Clinical trial of an air-circulating cooling blanket for fever control in neuro-ICU patients. Neurology 2001; 56 : 292-298.

11. Diringer M for the Neurocritical Care Fever Reduction Trial Group. Treatment of fever in the neurologic intensive care unit with a catheter-based heat exchange system. Crit Care Med 2004; 32: 559-564. 